\title{
Cleaning the Ion Exchange Resin Sorption of Uranium from Silicic Acid Solution “Ayanat”
}

\author{
Aibassov Erkin Zhakenovich*, Yemelyanova Valentina Stepanovna, Shakieva Tatyana, Tussupbaev Nessipbay, \\ Bulenbaiev Maxat and Blagikh Evgeniy \\ Research Institute of New Chemical Technologies and Materials, Kazakh National University Al-Farabi, Almaty 005012, Kazakhstan
}

\begin{abstract}
The authors discovered a new way to clean the ion exchange resin sorption of uranium from silicic acid used solution "Ayanat". The method reduces the costs of regeneration of ion exchange resin and its reuse in the sorption of uranium.
\end{abstract}

Key words: Ion exchange resin, sorption of uranium, silicic acid, cleaning.

\section{Introduction}

Significant complications during the sorption of uranium from acidic solutions bring silicic acid. The content of silicic acid is often so great (as ASTM-967 content permitted $\mathrm{SiO}_{2} 2.5 \%$ in respect to uranium), that in solutions in a relatively short time may form gels which gradually depending on the acidity of the solution and the content of silica formed solid structure gel and occupy the entire volume of ion exchange resin.

One of the urgent problems in underground sulfuric acid leaching of uranium and its processing further is the formation of silicic acid and ion exchange resin is clogged and reducing the sorption of uranium [1-8].

To solve this problem, we have chosen a solution "Ayanat" to remove the silicic acid from the ion exchange resin.

\section{Experiments}

In a plastic bottle with a capacity of $500 \mathrm{~mL}$ was poured $25 \mathrm{~mL}$ of ion exchange resin having $\mathrm{Si}=$ $11.793 \%$ and $\mathrm{U}=55.680 \%$, poured $100 \mathrm{~mL}$ of a $0.5 \%$ solution of "Ayanat" and stirred for $30 \mathrm{~min}$ at $25{ }^{\circ} \mathrm{C}$. The purified ion exchange resin is dried to constant

\footnotetext{
*Corresponding author: Aibassov Erkin Zhakenovich, professor, research field: metalorganic chemistry of uranium, As, Sb and Bi. E-mail: erkin53@mail.ru.
}

weight and analyzed for silicon content. The Si content was $2.000 \%$. Similarly, experiments were conducted with the regenerated ion exchange resin containing $\mathrm{Si}=7.492 \%$, after purification by silica absent $(\mathrm{Si}=0 \%)$.

\section{Results and Discussion}

We carried out experiments on ion exchange resin purification of silicon solution "Ayanat" at different temperatures. It has been shown that increasing the temperature to $60{ }^{\circ} \mathrm{C}$ purification rate of the silicon resin is increased to $100 \%$.

$\mathrm{X}$-ray source and purified by ion exchange resin content of the residual quantities of uranium and silica are shown in Figs. 1-5 and in Table 1 at various conditions and temperatures.

As seen from the table, with increasing temperature up to 60 degree from the ion exchange resin purification silicic acid is $100 \%$. This is due to the fact that as the temperature increases and increases the swelling of the resin solution "Ayanat" interact easily with the silicon by the reaction:

$4 \mathrm{HF}+\mathrm{SiO}_{2}=\mathrm{SiF}_{4}+2 \mathrm{H}_{2} \mathrm{O}$.

The result is the removal of silicon from the ion exchange resin.

Thus, our findings show that the solution "Ayanat" effectively clears the ion exchange resin from the 


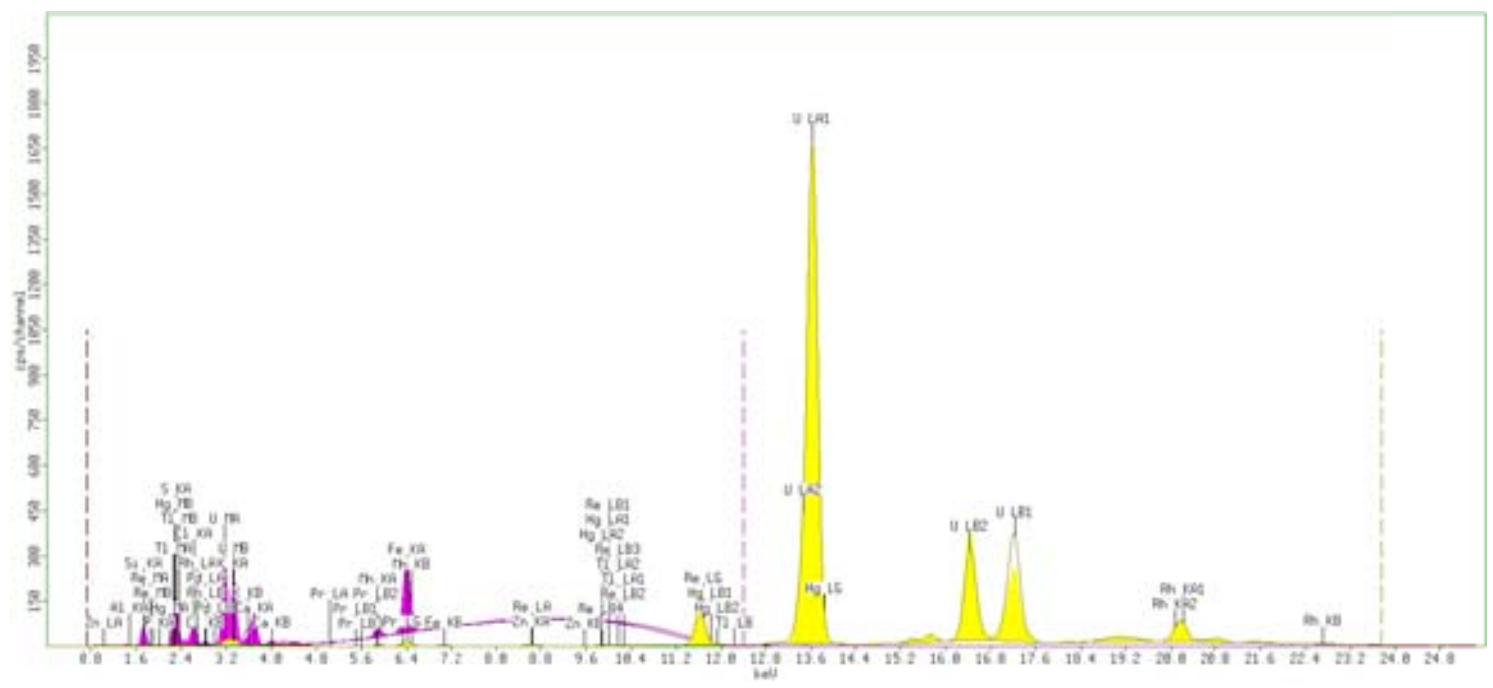

Fig. 1 X-ray spectrum of the original saturated ion exchange resins.

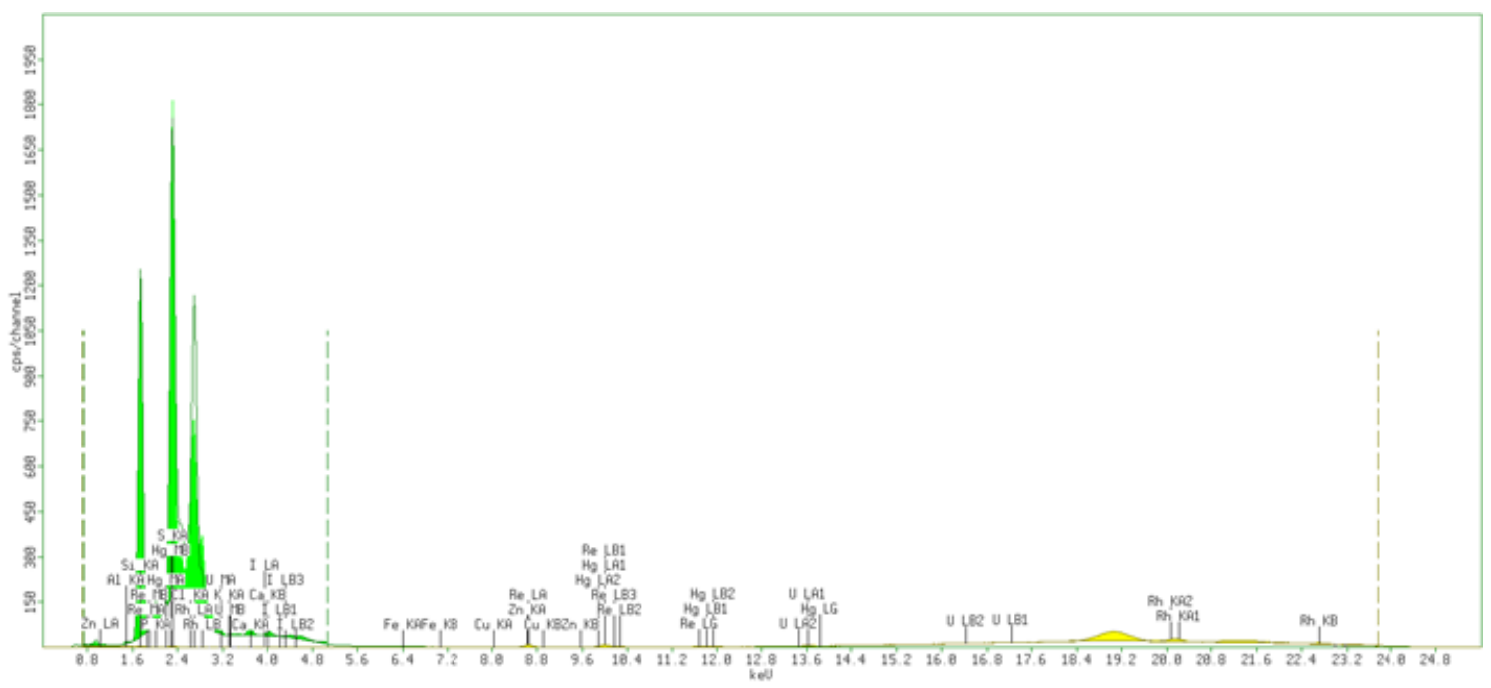

Fig. 2 X-ray spectrum of ion exchange resin saturated after cleaning $\left(25^{\circ} \mathrm{C}\right)$.

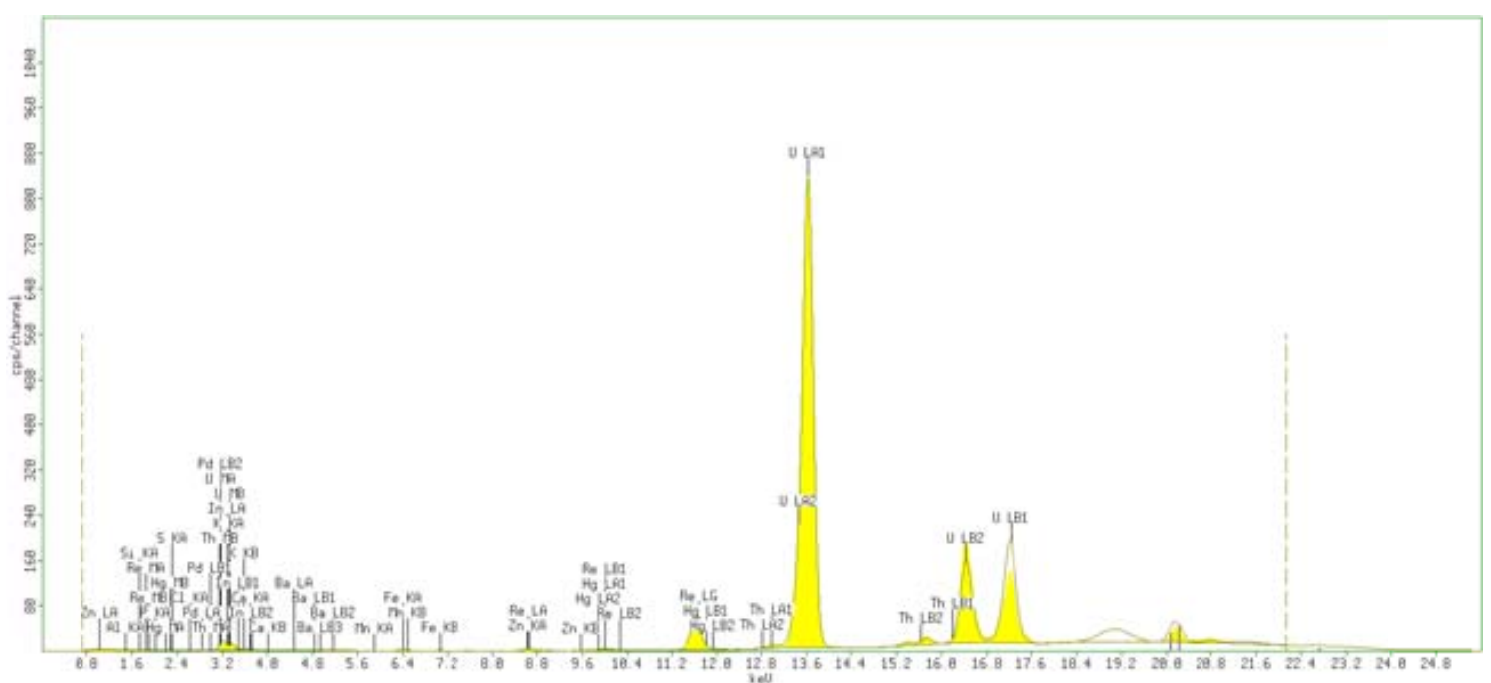

Fig. $3 \mathrm{X}$-ray spectrum of the initial regenerated ion exchange resins $\left(25^{\circ} \mathrm{C}\right)$. 


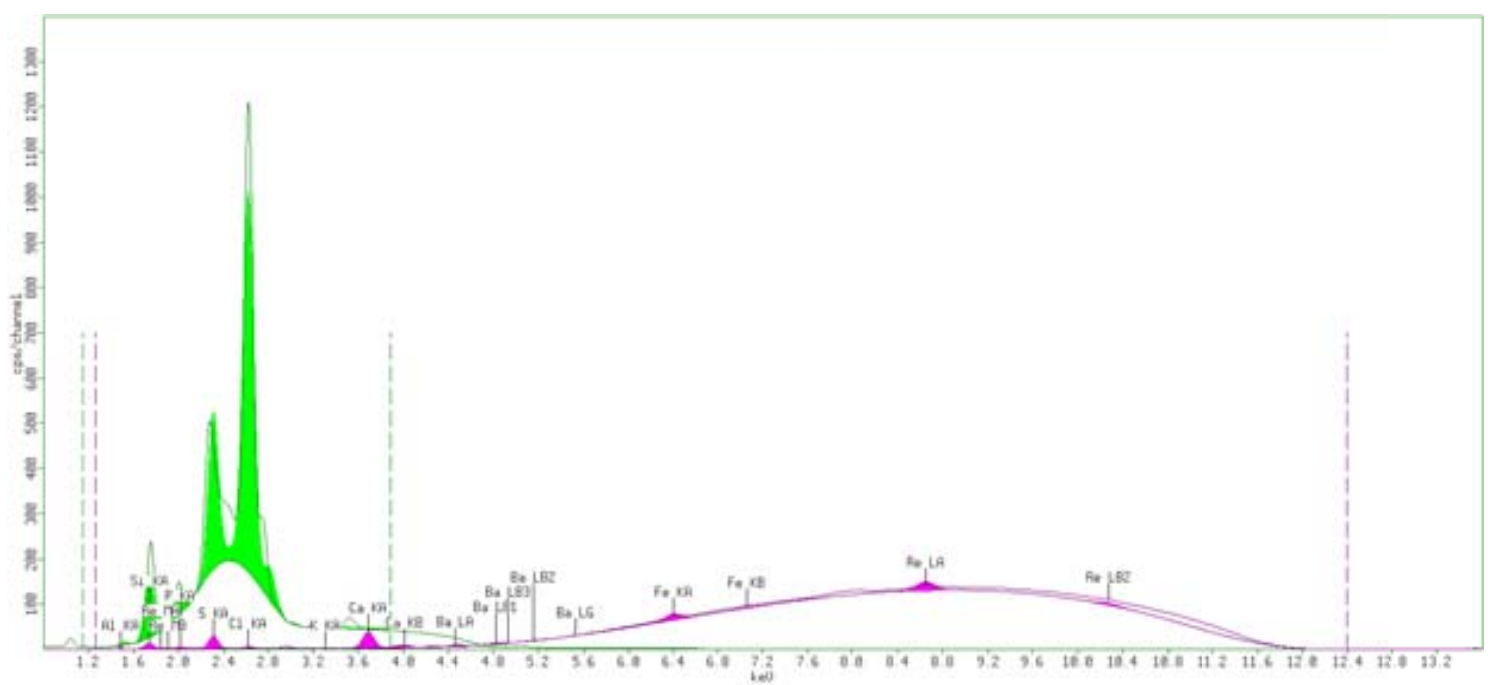

Fig. $4 \mathrm{X}$-ray spectrum of the regenerated ion exchange resin after purification $\left(25^{\circ} \mathrm{C}\right)$.

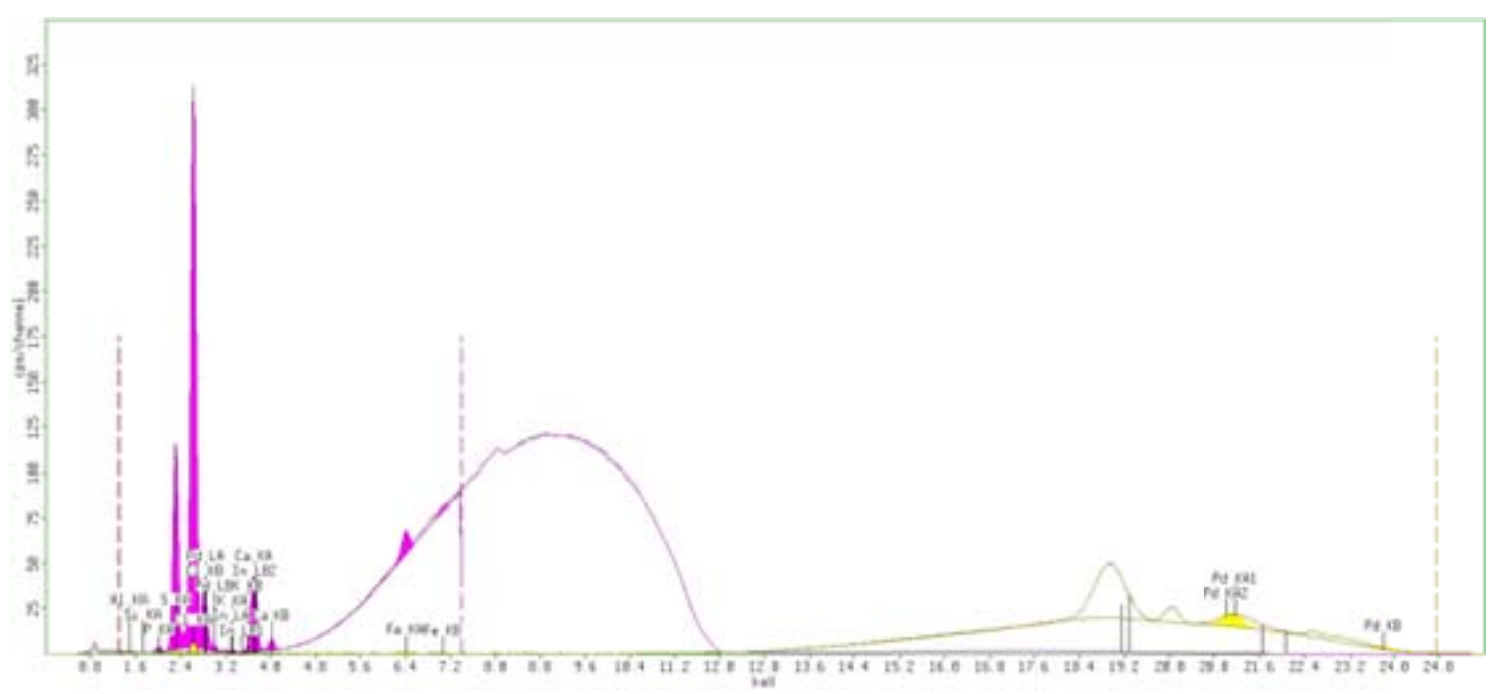

Fig. $5 \mathrm{X}$-ray spectrum of the regenerated ion exchange resin after purification $\left(60^{\circ} \mathrm{C}\right)$.

Table 1 X-ray source and purified by ion exchange resin.

\begin{tabular}{|c|c|c|c|c|c|c|}
\hline No. & & $\begin{array}{l}0.5 \% \text { solution } \\
\text { “Ayanat”, mL }\end{array}$ & $\begin{array}{l}\text { Temperature, } \\
{ }^{\circ} \mathrm{C}\end{array}$ & $\begin{array}{l}\text { Concentration } \\
\mathrm{U}, \%\end{array}$ & $\begin{array}{l}\text { Concentration } \\
\text { Si, \% }\end{array}$ & $\begin{array}{l}\text { Degree of } \\
\text { purification, \% }\end{array}$ \\
\hline 1 & Saturated resin (before cleaning) & - & 25 & 55,680 & 11,793 & - \\
\hline 2 & Saturated resin (after cleaning) & 100 & 25 & 33,588 & 2,009 & 82,96 \\
\hline 3 & Regenierated resin (before cleaning) & - & 25 & 0,016 & 7,492 & - \\
\hline 4 & Regenerated resin (after cleaning) & 100 & 25 & 0 & 1,076 & 85,63 \\
\hline 5 & Regenerated resin (after cleaning at $60^{\circ} \mathrm{C}$ ) & 100 & 60 & 0 & 0 & 100,00 \\
\hline
\end{tabular}

silicic acid. In the spring of 2015 it is planned to conduct pilot tests proyshlennye solution "Ayanat" to clean the ion exchange resin adsorption of uranium ions of silicic acid.

\section{Conclusions}

During the research, a new way to cleaning the ion exchange resin sorption of uranium from silicic acid used solution "Ayanat". The method reduces the costs of regeneration of ion exchange resin and its reuse in the sorption of uranium.

\section{Acknowledgments}

The authors would like to thank Ruben M. Savizky 
(Columbia University, New York) and Chistopher L. Cahill (George Washington University) for discussion of the results.

\section{References}

[1] Terrence, P. E. 2013. Acid regeneration of ion exchange resins for industrial applications. US Paten \# 20130192639 A1, filed December 13, 2011, and issued August 1, 2013.

[2] Gary, C. G., and Frederic, W. 2001. Using macroporous ion exchange resins that are both highly crosslinked and have a high water content; improved removal of weakly ionized ions, particularly silica, US Patent \# 6,312,577 B1, filed April 14, 2000, and issued January 29, 2001.

[3] Terrence, P. E., and Li, W. 2013. Acid regeneration of ion exchange resins for industrial applications, US Paten \# 20130146086 A1, filed December, and issued June 13,
2013.

[4] Mark, E. H. 2001. Gel-coated microcapsules. US Patent 6,270,836 B1, filed January 14, 2000, and issued August 7, 2001.

[5] Patric, B., and Markus, B. 2013. Emulsions for removal and prevention of deposits, EP Patent \# 2,606,182 A1, filed August 10, 2010, and issued June 26, 2013.

[6] Aibassov, Y., and Yemelyanova, V. 2014. "Magnetic and Relativictic Effects in Catalysis and Uranium Catalysts.” Germany, Saarbrucken: Lambert Academic Publishing, 160.

[7] Aibassov, E. Z., and Aibassova, S. M. 2011. "The New Reactions of Arsine." In Introduction to Organic Chemistry of Arsenic, Actinides, Lanthanides, $\mathrm{Os}^{187}$ and Re, $p 100$.

[8] Aibassov, Y., and Aibassova, S. 2013. Method of catalytic oxidation of $\mathrm{U}^{4+}$ to $\mathrm{U}^{6+}$ using a catalyst “Muhamedzhan-1”, Patent US \# 20130104698 A1, filed May 2, 2013. 